to the time of admission. The fits have all been preceded by "faintness at the chest," followed by flushings, on the occurrence of which insensibility has supervened. He once bit his tongue slightly. Has had no pain in the chest or elsewhere. He was ordered to take quinine and iron and two glasses of wine.-14th: I saw him to-day for the first time, and learnt that almost constantly since admission his pulse had been beating very slowly, sometimes not more than 26 in the minute, and that he had had frequent fits night and day. These had been of very short duration and attended with a little struggling. $\mathrm{He}$ had been carefully watched by several of the advanced students in some of these fits, and according to them it seemed clear that the fits always came on at the end of an unusually long interval between successive cardiac beats; that while the pulse was at the rate of one beat in three seconds, or even four seconds, no fit occurred; but that whenever, and only when, the intermission was prolonged to five seconds a fit followed at the end of that period. He is free from fits this morning, and his pulse is beating regularly at the rate of 26 in the minute. There is a loud roaring systolic murmur above and to the right of the apex, and prolonged thence to the base.-18th: No fit from the 14th to the 17th; but since the middle of yesterday, and especially during the night, the fits have been very frequent. They vary in length, but insensibility only lasts for a few seconds. He becomes very pale before each fit, then flushes, and while insensible his hands twitch a little. When I saw lim the fits had ceased, but the pulse was very irregular. A few regular beats at the rate of 80 in the minute were followed by one or two beats occurring at intervals of about three seconds. Systolic murmur loudest towards the base. A little later his pulse was quite regular at 80 per minute. -21st: Has had frequent fits night and day since the 18th, and has had several this morning. At the time of my visit the pulse is somewhat more irregular than it has been. There is an interval sometimes of three seconds, sometimes of four, without a beat, and then follows a succession of beats at the rate of 80 per minute. On listening to the heart, its sounds correspond accurately to the pulsations at the wrist; but between all the beats (attended with sound and perceptible at the wrist) separated from one another by intervals of between two and four seconds, there are one, two, or three slight impulses of the heart distinctly to be felt, and seen by the imparted movements of the stethoscope. These latter beats are wholly unattended by cardiac sound or pulsation in the arteries. It seems to me that the action of the heart is quite regular as to rhythm, but that many of its beats are ineffectual. These intermediate impulses are felt at the base of the heart; are they due to the action of the auricle or to the hardening of a relaxed but empty ventricle?-25th: Has been pretty free from fits, but had a slight one last night; slept well; feels better. Pulse about 80, but irregular. Rough murmur, loudest and roughest towards the base.-28th: No fits, but occasional sensation as if they were coming on. Pulse 58, regular.-June 1st: No fits; pulse 72 , occasionally a little irregular; murmur as before; complains of pain in left shoulder, running down inner side of the upper arm.-4th: No fits; pulse 72, quite regular ; feels much better.8th: No fits, but pulse irregular; murmur as before; feels well. On this day he left the hospital, but he attended as an out-patient until the 21 st. During this time, though his pulse continued to be somewhat irregular, he remained free from shortness of breath, palpitation, and fits, and expressed himself as feeling fairly well. I never heard of him subsequently. What my views of the morbid anatomy of the case were formerly I have not recorded, and do not recollect. I am inclined now to suspect that the cardiac disease was syphilitic.

It may be interesting in relation to the above case to record another in which similar epileptiform fits were the consequence of the opposite condition of temporary cerebral congestion. About ten years ago I was consulted by a gentleman sixty years of age, who was very fat and had been liable to bronchitis for many years. For several weeks or longer he had been suffering from severe prolonged paroxysmal attacks of cough with whooping inspiration, in the course of which he frequently became insensible and slightly convulsed for a few seconds. In my consultingroom one of these paroxysms of cough came on. It was much like an attack of whooping-cough, and after it had lasted for some time (half a minute or a minute) respiration suddenly ceased, he became increasingly livid in the face, his head fell upon his chest, and he was insensible and slightly convulsed for a few seconds. He then came to, and appeared in his usual condition. Whether he was really suffering from whooping-cough or not I do not know. I could not determine that point at the time, but I know that these phenomena continued unchanged for some considerable time after his visit to me, and that even during the next five or six years he still occasionally whooped, and still occasionally lost consciousness during severe attacks. I saw him again six years later, when he was suffering from the effects of advanced bronchitis, and about a month before his death from that disease. Attacks like the above are not uncommon, and occasionally cause death in children suffering from whooping-cough, but so far as I know they are rare in adults.

Your obedient servant,

Old Burlington-street, Feb. 16th, 1885.

J. S. BRISTOWE.

\section{"WHAT WAS THE CAUSE OF DEATH?"}

To the Editor of THE LANCET.

Sin,-As you have alluded to the case of the Norwegian sailor, Johnson, under the above heading in your issue of Feb. 21st, I hope you will allow me to explain briefly the facts. They are as follows:-

About 1 A.M. on the morning of Jan. 2nd the man, Johnson, was brought to the hospital, and found to be dead. On the 3rd, by the coroner's order, a post-mortem examination was made by me, at which there were present Dr. Little, honorary surgeon, and Mr. Gordon and Mr. Dixon, the two other house-surgeons. The examination occupied three hours, and every organ and every cavity was carefully examined. All those who were present were quite agreed as to the condition of the organs described below. What we found amounted briefly to this: Externally, several cuts and bruises about the head and face; internally, congestion of all the organs, considerable atheroma of the aorta, and nothing else. On Monday, the 5th, about 10 P.M., Dr. Whitford, called and said he had been engaged by the defence, and would like to see the body. Accordingly an appointment was made for eleven o'clock the next morning, the 6th. Dr. Whitford was not punctual, and before he arrived I had left for the coroner's court. However, he was shown the body by one of the other house-surgeons, and he made a hasty examination of the organs and the external injuries, the whole process occupying not longer than twenty minutes. The coroner's inquest was held the same day. The evidence of the witnesses was this: That one of the prisoners first engaged in an altercation with Johnson, and then the other two came to the assistance of the first; that Johnson was struck violently on the head several times with the buckle of a belt, and afterwards with a ginger-beer bottle, and that he died in a few minutes after receiving these injuries. After hearing this evidence I gave it as my opinion that the probable cause of death was concussion of the brain, and that the congestion of all the internal organs was due to his mode of death. Dr. Whitford then got into the box, and, without any previous communication with me, stated that he took a wholly different view of the matter; "that there was extensive and long-standing disease of the heart"; "that the left lung was nearly entirely semi-solid." When asked by the coroner to state the cause of death, Dr. Whitford replied, "I should find that difficult after all the examinations I have made, for none of the wounds I have found left sufficient traces of being enough to cause death. The deceased was much enfeebled by the condition of his lungs." The jury returned a verdict of "Wilful murder." In subsequent conversation with Dr. Whitford, I pointed out to him that the heart and the aorta were not quite the same, and I believe we agreed that the heart and its valves were healthy, but that there was considerable atheroma of the aorta. At the assizes Dr. Whitford described the left lung as "completely solid," and the right as "semi-solid." The jury without the least hesitation returned a verdict of "Manslaughter" against all the prisoners. On the next day Dr. Commins, addressing the Court in mitigation of sentence, was stating that the condition of the deceased man's lungs must have enfeebled him greatly, when he was interrupted by the Judge, who intimated that it was useless for counsel to pursue that argument, as the Court believed that the congestion of the organs was consequent on the assault.

To the questions asked in your article, I reply-1st. The congestion of the lungs was not greater than the congestion of the kidneys, and some of the other organs (which Dr. 
Whitford omitted to mention), and was the same in kind and degree as that which is frequently found in persons who have died a violent death. 2nd. There was no consolidation in either lung. 3rd. The aortic degeneration was not more than might have been expected in a man of deceased's age and mode of life. 4th. This last question Dr. Whitford answered at the assizes. He was asked, "If deceased had not received these injuries how long would he have lived?" He replied, "He might have lived a week ;" but as far as I can see there was no reason why he should not have lived for years. That the pathological changes found in the body had no apparent effect on the man's previous health may be assumed from the fact that he was considered by his wife to be a perfectly healthy man; and there can be no doubt whatever that he died from the effects of the brutal assault which was committed on him. For this assault there was no defence. $-1 \mathrm{am}$, Sir, yours faithfully,

F. KNIGHT, M.B. Lond.

Liverpool, Feb. 25th, 1885 . House-Surgeon, Royal Southern Hospital.

\section{MR. LEAKE AND THE AN'TI-VACCLNATIONISTS.} To the Editor of THE LANCET.

$\mathrm{SIR}_{4}$-I trust that you will permit me, in the public interest, as well as on professional grounds, to state what 1 know of the revaccination cases referred to by Mr. Leake. As the subject has now become public property, there cannot, I presume, be any reasonable objection to the exact circumstances being calmly narrated from the medical standpoint. On Nay 17th, 18s1, eight members of Mr. Leake's household were revaccinated by me, six on the 18th, and four, including Mr. Leake himself, on the 22nd. All were then residing in a large roomy house in Hill-street, Berkeley-square, taken for the season; as to its sanitary state I have no information. Two of Mr. Leake's relatives residing in an adjoining street were "done" on the 18th, and their maid on the $22 \mathrm{nd}$. To be exact, therefore, the operations numbered twenty-one, and, if I recollect rightly, at least one of the servants was, properly speaking, vaccinated. It was understood between Mr. Leake and myself that Brussels calf lymph was to be used, and I personally obtained the necessary supplies fresh as they were needed, in tubes, from Dr. Warlomont's agent in town. The operations were done by cross-scratching three places, at the usual distance apart from each other, over the deltoid, with the point of a clean Spratt's vaccinator; in one child, who did not look so strong as the rest, the lymph was applied in two places only. In short, every care and precaution was taken to ensure success.

On visiting the patients on May 23rd, 24th, 25th, and 26th, I found everything going on so well that I did not consider it necessary to call next day; but 1 left word that, if required, I was to be sent for at once. On the evening of the 27th my immediate attendance was requested. I found one of the servants, whom I had revaccinated on the $22 \mathrm{nd}$, ill in bed. She had complained in the morning, but the housekeeper did not report the illness until shortly before my arrival. The quickened pulse, high temperature, sore-throat, and as yet faint blush on the front of the chest, could not, and did not, fail to arouse suspicion; but I declined to express a final opinion till next morning. $\Lambda$ s there was then no longer any doubt that we had scarlatina to deal with, not a minute was lost The patient was quickly carried out of the house into the ambulance, which the London Fever Hospital sent at once in response to Mr. Leake's telegram. The bedclothes, \&c., were bundled up and cast out of the top back bedroom window into the garden, and finally removed through the stable; sulphur was burnt for hours in the bedroom; and either carbolic acid or Condy's fluid was thrown down the waterclosets and sinks. Nothing was left undone to prevent the extension of the outbreak, and we were happily successful. Now began our anxieties as to the possible consequences that might follow the importation of scarlatinahow we knew not--into a household passing, hitherto normally, through the vaccinal process. Unfortunately, on June 1st, or thereabouts, one of the daughters, aged about sixteen years, fell ill, the arm became reddish and swollen, and gradually the vesicles broke down into deep ulcerated sores discharging unhealthy pus. She was taken home to near Manchester on the 7 th, and her medical attendant there informed me in his letter of the 13th that a large abscess having a threatening aspect for a time formed in the axilla attended with erysipelas. There my information ends. I am under the impression that in another daughter the revaccination was a failure, owing to the vesicles running an irregular course, but after this lapse of time I am obliged to speak with some reserve. To the best of my knowledge and belief these two were the only patients out of twenty-one operated upon in whom the process, where it "took," did not pass through the normal phases. A third daughter accidentally made a very small puncture into the skin in front of the knee with the point of a pair of scissors. At that spot cutaneous erysipelas appeared, spreading downwards to the ends of the toes, and then upwards to the groin, where it stopped. This attack had no connexion whatever with the vaccinal puncture on the arm, which was unaffected. My last visit was on June 22nd.

If any of your readers have had a similar experience to the above, I hope they will make it known in your columns. My own opinion at the time, as stated to Mr. Leake, was that the untoward results just described could not, in fairness, be wholly, if at all, imputed to the lymph or the operation, but that the scarlatina had a good deal to answer for, and might have had more. The rule not to vaccinate in a house where scarlatina is known to prevail implies that scarlatina is hostile to vaccinia. There were no other cases of this disease at the time in the neighbourhood, to my knowledge.

As to the cost, my charges were ten guineas for twentyone revaccinations, and four guineas for four visits - that is, fourteen guineas. The visits subsequently made to the scarlatina patient and to the children numbered thirty-seven, which at one guinea each brought my claim up to fifty-one guineas; but I do not see how the revaccinations can be debited with more than fourteen. In order to err on the side of moderation I made no extra charge when 1 had to attend a good many times on two or more patients at the same visit. Mr. Leake's error seems to me to consist in the fact that he lays all the blame on the revaccination, and no blame at all on the scarlatina.

I am, Sir, yours obediently,

Hertford-street, Mayfair, March, 1885. $\quad$ GEO. Moone, M.D.

\section{RECOVERY AFTER APPARENTLY FATAL CHLOROFORM NARCOSIS.}

To the Editor of THE LANCET.

SIR,-Perhaps you may think the following instance of recovery from apparently complete death from chloroform worthy of insertion.

Some two years ago I was asked by a friend to remove a cataract from the eye of a favourite fox-terrier, the request being made with many apologies. I replied that I was as willing to give relief to the dog as to a human being, so the dog was brought. I found that it had necrosis of the central half of the cornea; so having chloroformed it, I made several incisions round the periphery of the necrosed portion. When I had finished, the dog was to all outward manifestation quite dead. My friend, Mr. W. O. Pughe, employed artificial respiration vigorously, but to no purpose. Suspending the animal by the heels had no better result. Artificial respiration was again tried, but still without avail. We next tried nitrite of amyl, but there was no response. All this had taken some time, and the case seemed hopeless, when it occurred to me to employ both artificial respiration and nitrite of amyl together. Two or three compulsory breathings of the amyl caused the dog to jump up and stagger about the room most actively. The eye recovered with scarcely an opalescence to mark the site of the necrosis. Since that time I have never knowingly given chloroform or had it given for me without having amyl nitrite at hand, although I am happy to say it has never been so imperatively necessary to use it as in the foregoing case.

I have seen only one case of chloroform death, and that occurred before the action of amyl nitrite was generally known; but I believe that had we treated the patient then as we treated the dog death would not have resulted. Now that ether has been used so much, is it not time to take stock to see whether it be so much safer than chloroform? My contention is that in the production of complete anæsthesia there is little or no difference between the two drugs, whilst in the after-effects, especially as regards vomiting, nausea, and depression of spirits, chloroform is much superior to ether. I am, Sir, yours truly,

Liverpool, Feb. 22nd, 1885. GEORGE E. WALKER, F.R.C.S. 